\title{
Linhas Criticas
}

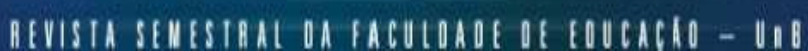

FATORES PSICO-SOCIAIS E PEDAGÓGICOS DA INDISCIPLINA:

DA INFÂNCIA À ADOLESCÊNCIA

PEDAGOGICAL AND PSYCHO-SOCIAL FACTORS OF INDISCIPLINE:

FROM CHILDHOOD TO ADOLESCENCE

LES FACTEURS PSYCHO-SOCIAUX DE L'INDISCIPLINE :

DE L'ENFANCE À L'ADOLESCENCE

\section{FATORES PSICOSOCIALES Y PEDAGÓGICOS DE LA INDISCIPLINA: DE LA INFANCIA A LA ADOLESCENCIA}

Maria Izete de Oliveira*

\begin{abstract}
RESUMO
O presente texto traz à tona a discussão de um tema que, há algumas décadas, vem interferindo de forma negativa na prática pedagógica dos profissionais da educação, causando conflitos não só na relação professor-aluno, mas nas relações dentro das instituições. Discutimos, primeiramente, de forma breve, o conceito de disciplina e indisciplina, defendendo uma postura democrática por parte do professor e participativa por parte do aluno. Em um segundo momento, abordamos alguns fatores psico-sociais e pedagógicos que interferem no comportamento da criança e que acabam culminando em indisciplina na sala de aula e na escola; ao mesmo tempo, apresentamos algumas propostas de prevenção e controle da indisciplina.
\end{abstract}

Palavras-chave: Indisciplina. Fatores psico-sociais. Fatores pedagógicos.

* Doutora em Psicologia da Educação pela Pontifícia Universidade Católica de São Paulo (2002). Professora do Programa de Pós-Graduação em Educação da Universidade do Estado de Mato Grosso (Unemat). Líder do grupo de pesquisa Estudo em Educação Infantil da Unemat - MT (mariaizete@gmail.com). 
Este artigo foi parcialmente extraído de uma pesquisa realizada com professores do ensino fundamental acerca da representação social sobre indisciplina escolar (OLIVEIRA, 2002; 2005). No entanto, não é nosso objetivo, aqui, discutir seus dados, mas apresentar uma reflexão sobre o tema com base nos resultados da pesquisa e na literatura da área.

\section{DISCUTINDO O CONCEITO DE DISCIPLINA/INDISCIPLINA}

Ao consultarmos o léxico, a definição que encontramos para o termo disciplina é "ordem, respeito, obediência às leis; matéria de estudo; instrumento de penitência" (Dicionário Escolar da Língua Portuguesa - Ministério da Educação), ou, ainda, "1. Regime de ordem imposta ou mesmo consentida. 2. Ordem que convém ao bom funcionamento duma organização. 3. Relações de subordinação do aluno ao mestre. 4. Submissão a um regulamento" (Dicionário Aurélio B. de H. Ferreira). Por isso, quando falamos em disciplina, tendemos a evocar as regras e a ordem que dela decorrem, como também as sanções que são aplicadas frente aos desvios de conduta.

Percebe-se nessas definições que o significado da palavra disciplina está vinculado a algo externo ao sujeito. Em geral, ela é imposta, ignorando as opiniões, os desejos e os valores daqueles que têm de se sujeitar a ela.

Nesse sentido, a disciplina está nitidamente ligada à indisciplina; enquanto a primeira é entendida, pelo senso comum, como a manutenção da ordem e obediência às normas, a segunda significa a sua negação, ou seja, a quebra da ordem. Esse entendimento sobre o conceito de disciplina e indisciplina é o que prevalece até hoje em determinados meios sociais.

Para auxiliar na nossa reflexão, cito o exemplo de um estudo realizado por Khouri (1989) com professores para saber a opinião destes sobre o que é ser um bom aluno. Na concepção dos professores, as características do bom aluno apontadas com frequência foram: "bem comportado, obediente, cumpridor de suas tarefas". Em contrapartida, o conceito de bom aluno como "ser crítico e reflexivo" aparece raramente nesses depoimentos. 
A princípio, essa concepção de bom aluno como sendo "bem comportado, obediente, cumpridor de suas tarefas" pode parecer apropriada, já que, se assim for, podese conseguir "dar uma boa aula" sem despender grandes esforços. Porém, se fizermos uma reflexão mais profunda, veremos que precisamos superar esse entendimento, pois temos como premissa que a questão da disciplina deve envolver a formação do caráter, da cidadania, dos valores e atitudes das pessoas.

É bom ressaltar, neste momento, que, seja qual for a nossa concepção de disciplina/indisciplina, ela estará sempre vinculada à concepção de educação e de cidadão. Se não queremos uma educação tradicional, de cunho autoritário, mas também não queremos uma educação permissiva e espontaneísta, nas quais o aluno não se sente responsável pelo seu processo de aprendizagem, então defendemos, de acordo com Woods (2001, p. 56), uma educação de abordagem fenomenológica, que:

[...] vê a criança mais como uma 'vela a ser acesa' do que como um 'recipiente a ser enchido', mais como um parceiro ativo do que um parceiro passivo no processo de aprendizagem. Nesta perspectiva, mais centrada na criança do que no saber ou no professor, a criança será desviante se for passiva.

Sem dúvida, essa é uma concepção coerente de educação, na qual o aluno não é visto como um receptor de informações, mas, ao contrário, ele é participativo. Nessa concepção, precisamos levar nossos alunos a descobrir, a associar, a discernir, enfim, a pensar... devemos despertar a curiosidade, a participação, o desejo e o gosto pelo saber.

Se o conceito de disciplina está imbricado em uma concepção de educação que valoriza apenas a transmissão dos conteúdos, então esse conceito de disciplina terá como base a submissão do aluno perante o professor e a valorização do silêncio e da ordem. Por outro lado, se defendemos uma concepção de educação que tenha como objetivo formar um cidadão que não só cumpra seus deveres, mas que também lute pelos seus direitos, que saiba discernir o justo e o injusto, que tenha consciência da realidade social em que vive, que reconheça que é transformado por ela e que pode contribuir para transformá-la, então 
o conceito de disciplina será aquele que valoriza o aluno participativo, crítico, ativo e que seja capaz de autodisciplinar-se.

Nesse caso, a "obediência" que se espera do aluno deve ser de natureza libertadora, pois, conforme Davis e Luna (1991), não existe liberdade intrínseca ao sujeito; ela se constrói na relação com os outros, uma vez que liberdade não é uma qualidade inata ao ser humano. Liberdade não é ponto de partida: é, antes, ponto de chegada, condição cotidianamente construída, e é no difícil e constante embate que a liberdade pode ser paulatinamente alcançada.

Paulo Freire, em um diálogo com educadores sobre esse tema, afirmou que "toda disciplina envolve autodisciplina. O sujeito da disciplina tem de se disciplinar. [...] $a$ indisciplina é a licenciosidade, é o fazer o que quero, porque quero. A disciplina é o fazer o que posso, o que devo e o que preciso fazer" (apud D'ANTOLA, 1989, grifo nosso). Nessa concepção, o aluno é considerado uma pessoa ativa no processo de aprendizagem; a relação de dominação e submissão da concepção tradicional dá lugar ao respeito mútuo entre professor e aluno.

\section{ALGUNS DETERMINANTES DA INDISCIPLINA}

Diante desse contexto, para dar continuidade a nossa reflexão, faz-se necessário esclarecer o que entendemos por indisciplina. Na nossa concepção, o aluno indisciplinado é aquele que não desenvolveu a autodisciplina, que não tem consciência dos efeitos do seu comportamento para o seu aprendizado, que não consegue discernir o certo do errado, que não respeita os princípios da democracia em um ambiente social e que, em consequência disso, acaba agindo de forma irresponsável, atrapalhando o andamento das aulas com atos de desrespeito, vandalismo e agressão.

Não pretendemos, aqui, adotar uma posição simplista e ingênua, ditando normas ou regras que os profissionais da educação devem seguir para solucionar o problema. Porém, se os professores tiverem clareza de alguns fatores que causam indisciplina, poderão perceber o porquê das atitudes "desviantes" dos alunos, ou seja, conhecer as raízes dos problemas daqueles que são rotulados de indisciplinados, como também fazer uma auto-reflexão sobre sua prática frente a esse tipo de comportamento. 
É importante ressaltar que, de acordo com estudos da área da psicologia, adolescentes que geram problemas constantes na escola, geralmente, começam a apresentá-los em idade precoce. Alguns sinais podem aparecer em crianças a partir dos três anos de idade: hiperatividade, instabilidade emocional e agressividade.

De acordo com Oliveira (2005), a transformação histórico-social e as mudanças pedagógicas interferiram nas relações dentro da escola e, consequentemente, nas atitudes dos professores, que vão interferir, também, no comportamento das crianças, prejudicando a relação professor/aluno e aluno/aluno e, por vezes, acabam culminando em indisciplina.

Logo, entendemos que são diversos os fatores que levam os alunos a cometer atos de indisciplina, e esses fatores não atuam, necessariamente, com a mesma intensidade no comportamento da criança ou adolescente; alguns podem ser mais ou menos extremos, conforme a circunstância e a realidade de cada aluno e de cada escola. Eles podem ser, ainda, de origem interna ou externa à instituição. Assim, para melhor compreensão desses fatores, dividimo-los em dois blocos: psico-sociais e pedagógicos.

\subsection{Fatores psico-sociais}

\subsubsection{A família}

Quando mencionamos a família não estamos, necessariamente, referindo-nos à concepção tradicional, com a presença do pai, da mãe e dos filhos, pois se sabe que essa estrutura familiar vem sofrendo transformações, e o modelo nuclear de família já não é mais referência para as nossas crianças. O ambiente familiar ao qual nos referimos é aquele em que a criança convive com alguém responsável por ela, podendo ser pais, avós, tios, irmãos, padrinhos, entre outros, pois serão essas pessoas que a criança tomará como exemplo e que influenciarão em sua conduta.

Há, ainda, casos em que os pais/responsáveis passam o dia fora de casa à procura de emprego ou trabalhando para garantir o sustento da família, não lhes sobrando tempo para se dedicarem aos filhos. Em geral, em casos como esses as crianças passam o dia todo sozinha, em casa ou na rua. E os pais/responsáveis transferem para a escola a responsabilidade da educação de seus filhos: estabelecer limites e desenvolver hábitos 
básicos. Fica a cargo do professor ensinar às crianças desde amarrar os sapatos, dar iniciação religiosa até colocar limites que já deveriam vir esclarecidos de casa.

Queremos chamar a atenção, também, para o fato de que nessas famílias que se encontram desorientadas e desestruturadas muitas pessoas são alcoólatras, drogadas, violentas e, às vezes, agridem-se frente às crianças. Além de os responsáveis por cuidar e educar as crianças muitas vezes se agredirem, o pior é que a criança também é agredida por eles. Conforme informações obtidas no Conselho Tutelar da Infância e Juventude da Cidade de Cáceres - MT, lamentavelmente, " $53 \%$ das vítimas de violência, são crianças na faixa etária de 0 a 11 anos; $58 \%$ dos atos de violência contra crianças e adolescentes são praticados por pais ou responsáveis; $57 \%$ das crianças e adolescentes vítimas de violência estão matriculadas e frequentam aulas em escolas da rede pública" (grifo nosso).

Há, também, situações opostas a essas: o excesso de mimos, a superproteção e a permissividade por parte dos pais/responsáveis também acarretam problemas de comportamento nessas crianças em casa e na escola. A criança educada dessa forma acha que todos estão a seu dispor para atendê-la e que não tem regras a seguir, tudo gira ao seu redor, ela é o centro das atenções.

Em ambos os casos, os pais ou responsáveis não sabem como impor limites e esclarecer às crianças que elas têm direitos, mas também deveres a cumprir. Assim, no momento em que as crianças iniciam a vida escolar, levam consigo seus valores, hábitos, condutas, inseguranças, angústias, traumas e revoltas, que são reflexos de uma educação recebida no ambiente familiar. Por outro lado, um ambiente familiar em que "pais" e filhos se relacionam bem, respeitando-se mutuamente, onde há afeto e estabelecimento de limites, facilita a criação de um clima de equilíbrio emocional dentro de casa, o que ajuda no bom comportamento e desempenho dos filhos na escola.

Em suma, interessa ressaltar que a "educação oferecida" pelos responsáveis reflete na relação da criança com os colegas e com os professores, podendo gerar atitudes indesejáveis na escola que culminam em desobediência, agressividade, falta de respeito perante os colegas, os educadores e funcionários da escola.

Entretanto, é preciso entender que a família é vítima de uma sociedade violenta, injusta, repressiva, e que as atitudes dos pais/responsáveis sofrem influência desse meio social; o mesmo processo histórico-social que desestruturou a sociedade, as 
instituições, as organizações sociais, a escola, desestruturou e vem desestruturando as famílias.

\subsubsection{A mídia}

Por outro lado, quando os pais tentam estimular nas crianças uma educação respaldada em valores morais e éticos, a mídia, mais especificamente a televisão, tende a dificultar essa prática. As emissoras de TV, por meio de sua programação inescrupulosa, que tem como único objetivo aumentar seu ibope, incentiva a rebeldia, a competição, o individualismo, o sexo e a violência.

A violência é transmitida às crianças através dos desenhos animados, aos jovens através dos filmes e aos adultos através dos noticiários, levando a uma banalização da violência e da agressividade, sendo a indisciplina na sala de aula uma das manifestações desta situação (JESUS, 1999, p. $48)$.

Às vezes o professor presencia cenas de violência entre os alunos e não se dá conta de que eles podem estar simplesmente reproduzindo, dentro da escola, aquilo que viram na programação da TV, seja em filmes, seja em desenhos animados. Não são raros nos noticiários, nacionais ou estrangeiros, os casos de adolescentes que atiram e matam colegas e pessoas inocentes após assistirem a filmes e notícias de assassinatos compulsivos na televisão.

Há pessoas que defendem que a responsabilidade não é das emissoras, mas dos pais que permitem a seus filhos menores assistirem a programações impróprias para sua idade. Porém, como os pais poderiam exercer esse controle sobre seus filhos se eles, como já mencionamos, em sua maioria, passam a maior parte do tempo fora de casa trabalhando ou à procura de trabalho?

\subsubsection{A diversidade entre os alunos}


Quando falamos de diversidade nos referimos, por exemplo, às diferentes culturas com as quais nos defrontamos no âmbito escolar. Sabemos que, mesmo em escolas públicas de periferia, que atendem crianças de uma mesma comunidade, não existe a homogeneidade, já que todas as pessoas são providas de sentimentos, desejos, ambições, crenças e valores e são imbuídas de costumes e práticas que adquirem no seu ambiente familiar e social (modos de agir, linguagem, gestos, atitudes, hábitos de higiene) que desde cedo vão formando sua personalidade.

Esse é um fator com o qual os profissionais da educação devem se preocupar, pois, comumente, o professor não tem preparo para lidar com a diversidade e acaba determinando, às vezes inconscientemente, como aceitável o comportamento daquele aluno cujas atitudes e costumes demonstram proximidade com os seus valores, ou seja, com aquilo que ele julga ser o certo. Nesse caso, pode ocorrer que um aluno que não se enquadra no "modelo" estabelecido pelo professor passe a ser discriminado, fazendo com que o professor manifeste, mesmo que implicitamente, uma predileção por um ou outro aluno. Isso acaba prejudicando as crianças que são discriminadas, pois o professor passa a adotar tratamento diferenciado para os alunos.

Essa discriminação pode ocorrer não só em relação à cultura da criança, mas também no juízo que o professor faz do aluno, seja por sua aparência, pelo modo de se comportar, seja pela forma como se expressa, pela sua dificuldade em aprender os conteúdos, e tudo isso pode causar grandes conflitos em sala de aula.

Nesse sentido, Carraher (1989), quando trata das diferenças individuais dos alunos de classes sociais distintas, fala da "contracultura escolar" criada pelo aluno da classe trabalhadora: a tentativa de desenvolver estratégias para lidar com a monotonia e os empecilhos, levando-os a adotar comportamentos que são a inversão das regras institucionais, como, por exemplo, fumar, vestir-se de modo "inadequado", faltar às aulas, namorar na sala, praticar o vandalismo, pequenos furtos e agir agressivamente.

Entretanto, essa não é uma regra geral dos alunos se comportarem frente às imposições da instituição e dos professores. Os alunos reagirão de formas distintas dependendo de sua característica pessoal: ou se conformam, submetendo-se a todas as tarefas, ou se rebelam contra as e imposições. Seja qual for o comportamento adotado pelo aluno, uma coisa é certa: nos dois casos ele será o maior prejudicado, pois será visto como diferente, seja por sua submissão, ou pelo vandalismo e agressão, e será rotulado e 
discriminado pelos colegas e professores, o que poderá agravar cada vez mais esse tipo de comportamento.

Os profissionais da educação não podem se esquecer de que o aluno não é um "vazio"; ele tem hábitos e atitudes que, por terem sido apreendidos no seu meio social e familiar, são aceitos nesses ambientes. E esse comportamento, natural do aluno, às vezes é considerado pelos professores como grosseiro, rebelde, ou seja, 'sem modos'. Isso, muitas vezes, ocorre porque a criança se comporta a seu modo dentro da escola e não conhece, ou não entende, certos princípios de ordem e exigências dessa instituição e, em contrapartida, o professor ignora a realidade do aluno.

Paulo Freire (1997) ressalta que a resistência do professor em respeitar a 'leitura de mundo' com que o educando chega à escola, obviamente condicionada por sua cultura de classe e revelada em sua linguagem, constitui-se em um obstáculo ao conhecimento. Ou seja, além de todo o conflito que a diferença social e cultural causa na relação professor-aluno, ainda apresenta a agravante de dificultar o aprendizado, já que, na tarefa de ensinar, o professor não considera a experiência de vida dos alunos.

Esses conflitos entre alunos e professor acabam por culminar em desinteresse pela escola, passando a ser encarada pelos educandos como um dever, uma obrigação, e não como um direito ou algo prazeroso. Não estamos dizendo que devemos aceitar tudo que vem dos alunos, mas que devemos abordá-los com sabedoria e bom senso, procurando não humilhar uma criança que muitas vezes já se sente inferiorizada pela vida que leva.

Outra situação gerada entre os alunos por causa da diferença pessoal/física a que o professor deve estar atento para coibi-la é o bullying. Bullying é uma palavra inglesa que significa "amedrontar, intimidar"; é uma ação da turma toda, ou quase toda, contra uma determinada criança, no sentido de provocá-la e intimidá-la por meio de ameaças. A criança vítima do bullying se vê acuada, sem poder reagir. É uma atitude de discriminação que a classe faz em relação a uma criança tida como "diferente" na sala de aula. Essa diferença pode ser em relação a porte físico (criança gorda ou magra demais, alta ou baixa, negra, albina) ou, ainda, em relação ao seu desempenho em sala de aula, como, por exemplo, a dificuldade na aprendizagem. Muitas vezes, o professor, sem ter consciência da gravidade desse fato, acaba por reforçar essa ação, chamando o aluno por apelidos pejorativos, como gordinho, baixinho, escurinho, entre outros. A agravante nesse caso é que o aluno será rotulado pelos colegas e, às vezes, pelo professor, e esse estigma ele 
carregará consigo pelo resto dos anos escolares e de sua vida, o que irá interferir na sua auto-estima e na sua relação social. Assim, o bullying pode gerar uma patologia, e a pessoa necessitará de acompanhamento psicológico para superar ou amenizar as sequelas deixadas pela discriminação sofrida.

Outro fator relativo a diferenças individuais a que o professor precisa estar atento é que nem todos os alunos terminam a tarefa ao mesmo tempo, e proporcionar atividades extras para os alunos que terminam a tarefa antes dos colegas reduz a probabilidade de mau comportamento. Assim, é aconselhável organizar atividades pedagógicas diversificadas (jogos educativos) para os alunos mais rápidos, evitando o seu desassossego ao término da tarefa. O professor tem que partir do princípio de que os alunos têm diferenças individuais e tentar situar seu trabalho nas condições reais da turma.

O bom senso e a experiência podem ajudar no gerenciamento de sala de aula. Manter os alunos sempre ocupados com atividades que lhes interessam e que exijam concentração pode ser um fator fundamental para evitar a indisciplina. O professor deve preparar sua aula antes de entrar em sala procurando prever a dosagem, o nível de dificuldade e a duração de cada atividade, evitando o seu excesso ou a ociosidade dos alunos.

\subsubsection{Problemas de distúrbio de atenção}

A capacidade do professor de identificar comportamentos considerados “desviantes", advindos de fatores psicológico ou físico e que se configuram em distúrbio de atenção é imprescindível para que ele possa tomar atitudes adequadas que ajudem a criança e minimizem o problema.

Um caso de comportamento característico de distúrbio de atenção é, por exemplo, aquele em que a criança apresenta hiperatividade que prejudica a sua capacidade de concentração e atenção. Crianças e adolescentes que apresentam problemas visuais, auditivos, dificuldades de aprendizagem, entre outros, também podem revelar dificuldades na sua capacidade de concentração e atenção.

Atualmente, com a política de inclusão das crianças que apresentam necessidades especiais em escolas comuns, há de se levar em conta que em qualquer sala de aula pode haver um aluno com distúrbios de atenção de natureza variada, que precise 
de acompanhamento especial, já que esses alunos, em sua maioria, não conseguem acompanhar o andamento da aula.

Se os educadores souberem diagnosticar esses distúrbios e ajudar no encaminhamento dessas crianças a um tratamento especializado estarão não só ajudandoas a superar ou lidar com o problema, como também evitarão que o comportamento delas culmine em indisciplina, influenciando negativamente o comportamento dos colegas. Entretanto, os professores têm que ter cautela para não encaminhar para tratamento crianças que tenham alguma dificuldade de aprendizagem, mas que, às vezes, precisam apenas de um pouco mais de atenção do professor e da família.

De acordo com José e Coelho (2006), os distúrbios de comportamento são classificados em duas categorias principais. O problema de conduta, que é caracterizado como aquele que perturba totalmente as outras pessoas, podendo ser dirigido contra elas, como a hostilidade, a agressividade, a destruição, a delinquência e a psicopatologia. Esses problemas podem ser identificados facilmente pelo professor e familiares porque chamam a atenção. O problema de personalidade é de caráter neurótico e pode ser chamado de "comportamento esquivo", ou seja, a criança tem medo dos outros, sente-se ansiosa, evita situações que possam expô-la à crítica, ao ridículo ou à rejeição, podendo tornar-se hostil quando submetida a um alto grau de tensão. Esses problemas são mais difíceis de serem constatados, pois geralmente a criança apresenta-se submissa e obediente.

Sabemos que detectar esses problemas não é uma tarefa fácil e que os professores enfrentam muitas dificuldades no seu cotidiano e, às vezes, não têm a quem recorrer na escola para compartilhar seus problemas. Mas, se os educadores ignorarem essas crianças, deixando-as de lado ou tratando-as como as demais, no que diz respeito à aprendizagem, poderão dificultar ainda mais sua prática pedagógica, pois enfrentarão outros tipos de problemas em sala de aula.

\subsubsection{Carência afetiva}

Outro fator a ser considerado é que boa parte de nossas crianças apresenta uma carência afetiva muito grande, já que não puderam contar com os pais para lhes dar carinho, atenção, nem tampouco ouvi-las. Essa falta de carinho e de atenção que algumas crianças sofrem em casa pode, naturalmente, culminar em problemas de comportamento 
na escola. Isso ocorre porque a criança irá tentar a todo custo conquistar na escola o que não consegue em casa: a atenção das pessoas a sua volta. E ela fará o que for possível para atingir esse objetivo, ou seja, agirá das mais diversas formas para chamar a atenção dos colegas e professores.

Ciente desse fato, o professor poderia proporcionar uma relação afetiva com a turma, demonstrando seu interesse pelos alunos, chamando-os pelo nome, mostrando-lhes que estão sendo notados em cada momento, entre outras ações. Não devemos tratar nossos alunos como se fossem um amontoado de crianças sem particularidades, o vínculo afetivo em sala de aula é fundamental para que o trabalho flua.

Se o professor souber ouvir o aluno sobre suas dificuldades pessoais ou escolares já favorecerá, em muito, o relacionamento e o clima de sala de aula. Não se trata de atender as vontades dos alunos, mas de aproximar-se deles e conhecer suas dificuldades e sua realidade para melhor exercer seu papel de educar.

O elogio, por exemplo, é uma forma de afetividade que ajuda a despertar no aluno a sua auto-estima positiva e o gosto em aprender. Seja em público ou em particular, o elogio desperta na criança um sentimento de potencialidade e de aceitação. Isso, provavelmente, fará com que o aluno se envolva cada vez mais nas atividades escolares, diminuindo a indisciplina na sala. Ao reconhecerem esse fato, os professores poderiam passar a valorizar e a destacar, de maneira sutil, por meio de elogios, mas sem comparações, os alunos atentos e participativos como forma de despertar na turma as vantagens de ser "bem comportado".

Mas a afetividade por parte do professor não o faz abdicar de sua responsabilidade e de sua autoridade. Paulo Freire (1997) ressalta que a prática educativa vivida com alegria e afetividade não prescinde da formação científica séria e da clareza política dos educadores. Enquanto os professores não perceberem que é, também, por meio da dinâmica relacional do docente com a turma e da análise detalhada do que se passa no seio do grupo que podem melhorar o ambiente de sala de aula, não obterão grandes resultados.

Um fato relatado por Strecht (2001) que se traduz em um exemplo muito claro do que estamos defendendo é o caso de uma aluna que cursava a primeira série do ensino fundamental e gostava muito de sua professora. Ela dizia que sua professora tinha o mesmo nome de sua mãe e, várias vezes, enganava-se e a chamava de mãe, e a professora 
respondia chamando-lhe, carinhosamente, de "filhota". No final do ano letivo, quando essa aluna soube que ia mudar de sala e de professora, despejou um tubo de cola em cima da mesa da professora e deitou-se nela, ficando, literalmente, colada na mesa.

Esse é um exemplo de atitude considerada desviante para o professor que não tem conhecimento do contexto dessa situação, qual seja: a relação de afetividade que professora e aluna mantinham. Mas, para a aluna, foi um ato de desespero e apelo, que carrega em si muito significado, pois, sem saber como conservar aquela relação e a proximidade com a professora, resolveu colar-se em sua mesa, que, para ela, era o objeto que representava a presença da professora.

\subsection{Fatores pedagógicos}

\subsubsection{Imposição ou falta de regras}

Para D’Antola (1989), os bons professores estabelecem bem as regras e dão diretivas mais precisas; apresentam claramente suas expectativas quanto aos comportamentos dos alunos; respondem a estes de forma consistente; intervêm mais prontamente para parar o desvio e utilizam mais frequentemente as regras em caso de indisciplina.

Mas, geralmente, as regras sequer são explicitadas ou discutidas com os alunos. O que comumente acontece na escola é que, quando se inicia um ano letivo, não há esclarecimentos, por parte dos educadores, sobre o que se espera dos alunos, como também não há orientação sobre as condutas que garantam o bom funcionamento do processo ensino/aprendizagem, como, por exemplo, o respeito entre os que estão envolvidos no cotidiano escolar.

Talvez essa falta de orientação ocorra porque nem mesmo a equipe pedagógica tem claros os princípios que devem nortear o comportamento dos alunos. Muitas vezes não é promovida, na escola, nenhuma discussão prévia entre os educadores para refletir e tomar decisões conjuntas a esse respeito. Essa falta de orientação faz com que cada professor haja da forma que mais lhe convém, utilizando-se apenas de sua experiência e bom senso. 
Assim, os educadores, tendo como parâmetro os seus próprios princípios e valores, adotam normas que devem ser cumpridas pelos alunos, determinando um padrão de comportamento aceitável pela instituição, o qual servirá de parâmetro para a elaboração das regras a serem seguidas em sala de aula e na escola.

Mas se a escola recebe os alunos com as regras já estabelecidas, sendo estas rígidas e incontestáveis, dificilmente a criança vai se adequar àquilo que a escola espera dela. Por isso, na elaboração das regras, devemos ouvir e respeitar a opinião dos alunos, pois esse deve ser um processo democrático e resultar do consenso entre os professores e os alunos quanto ao comportamento que se espera deles, ou seja, o que deve, ou não, ser considerado indisciplina. Conforme o Referencial Curricular Nacional para a Educação Infantil - RCNEI, "promover debates em que as crianças possam se pronunciar e exprimir suas opiniões até que se coordenem os pontos de vista para o estabelecimento de regras comuns, é um procedimento a ser assegurado no planejamento pedagógico" (BRASIL, 1998, p. 15).

Somente reconhecendo-se como responsáveis pela elaboração das normas os educandos irão respeitá-las. Por isso, é fundamental que eles tenham consciência da necessidade do estabelecimento de regras e de sua participação nesse processo, já que estas devem ser seguidas por eles para proporcionar um ambiente saudável para a aprendizagem.

Para tanto, é preciso ajudar nossos alunos a fazer a passagem da heteronomia característica de pessoas que aceitam prontas as regras de conduta sem discussão, sem procurar entender as razões que as justificam, para a autonomia, que é a capacidade de se conduzir e tomar decisões, levando em conta não só as regras, mas sua perspectiva pessoal e a perspectiva do outro (BRASIL, 1998). O RCNEI preconiza, ainda, que desenvolver a autonomia já na faixa etária da educação infantil é mais do que um objetivo a ser alcançado, devendo ser um princípio das ações educativas, ou seja, precisamos ajudar nossos alunos a alcançarem a autodisciplina com responsabilidade.

\subsubsection{Formação docente quanto às questões relacionais}

Se o professor tem dificuldade em lidar com toda essa complexidade do ambiente escolar e com a diversidade, certamente uma parcela da responsabilidade cabe 
aos cursos de formação de professores. Esses cursos, muitas vezes, não preparam o futuro educador para desenvolver seu trabalho pedagógico de acordo com a realidade dos educandos.

Nos cursos de formação, a preparação do professor para os aspectos relacionais, incluindo a indisciplina, é tratada de forma superficial; muitas vezes esses cursos não alertam para a problemática da relação professor-aluno, para as causas da indisciplina e da violência que ocorrem dentro das escolas, para as formas de prevenção, e não orientam para um gerenciamento de sala de aula que envolva motivação e participação dos alunos.

Uma formação voltada para uma atuação profissional mais consciente e ativa, na qual o professor deixe de ser um mero transmissor de conhecimento, poderia diminuir o problema da indisciplina dentro da sala de aula. Esse procedimento, na formação do educador, seria o que podemos chamar de medida de prevenção da disciplina, que, acreditamos, traria melhores resultados do que as medidas de correção ou punição frente às condutas já instaladas.

Não existindo uma formação pedagógica orientada por princípios de prevenção da indisciplina, o "mau" comportamento que algumas crianças apresentam no início da vida escolar pode se agravar, já que os professores não estarão preparados para lidar com determinadas atitudes dos alunos e estarão desprovidos de habilidades para o gerenciamento de sala de aula. Nesse caso, sentindo ameaçada a sua autoridade, o professor poderá adotar práticas autoritárias e repressivas que podem gerar novos conflitos.

Assim, para evitar contradições nas ações dos professores, seria interessante promover a formação permanente e em serviço voltada para a reflexão, análise e resolução dos problemas que os afligem, como a indisciplina, a violência, a dificuldade de aprendizagem dos alunos, as metodologias de ensino, a política de inclusão, entre outras ações, para que pudessem ampliar os horizontes para uma ação mais consciente.

\subsubsection{A proposta pedagógica do professor}

A ausência de uma proposta pedagógica bem elaborada pode ser outro determinante da indisciplina. Os conteúdos ministrados e a metodologia utilizada muitas 
vezes não condizem com as expectativas e a realidade dos alunos, ou seja, os alunos não conseguem entender para que aprender determinadas matérias que não fazem sentido algum para sua vida cotidiana. E a forma como são transmitidas agrava ainda mais esse desinteresse, pois os conteúdos, com raras exceções, são passados de maneira fragmentada e desvinculados da realidade dos educandos. Nesse caso, o professor é visto como o detentor do conhecimento, sendo encarregado de transmiti-lo aos alunos, que são considerados meros receptores dessas informações.

A história, por exemplo, comumente, é transmitida de forma estagnada e acrítica. Muitos professores, salvo raras exceções, não fazem uma relação da história com outras disciplinas, nem entre os diversos fatos históricos; tampouco falam de sua influência no nosso presente e no nosso futuro. Ela é transmitida como se fosse linear, pronta e acabada, deixando de lado o seu dinamismo. Da forma como é ensinada, parece que não somos sujeitos da nossa própria história; estamos alheios a ela. Isso afeta diretamente o desenvolvimento da consciência e causa profundo desinteresse nos educandos, pois não percebem a forma como os fatos se desenvolvem, a influência que exercem em nossas vidas, além de não terem clareza de que exercer sua cidadania é fazer história.

Outro exemplo muito comum é o da matemática, que geralmente é transmitida de forma mecânica, fazendo com que a maioria dos alunos encontre grandes dificuldades no seu entendimento e tenha aversão a essa matéria (CARRAHER, T.; CARRAHER, D.; SCHLIEMANN, 1993). Acreditamos que esse problema ocorre pelo fato de que, infelizmente, alguns professores não sabem justificar a necessidade de se ensinar determinados conteúdos e acabam usando justificativas evasivas, dizendo que é matéria obrigatória do programa ou que vai cair na prova.

É certo que queremos alunos que saibam se comportar e reconheçam que há momentos em que são necessários concentração e esforço para que a aprendizagem ocorra, mas isso não significa aluno passivo e silencioso o tempo todo, e sim o aluno participativo e concentrado numa atividade significativa e interessante.

Para que os alunos tenham interesse pela matéria, é preciso que o professor saiba qual a sua importância para a vida dos educandos e discuta com eles a razão de ser de cada conteúdo estudado. O educador precisa assumir uma prática "progressista”, na 
qual é tarefa docente não apenas ensinar os conteúdos, mas também ensinar a pensar a raciocinar.

Mas por que discutir com os alunos a razão de ser dos conteúdos? O que isso tem a ver com a indisciplina? Ora, sabemos que a forma acrítica e passiva como normalmente são transmitidos os conteúdos leva o educando ao desinteresse pela matéria e, consequentemente, à dificuldade em se concentrar e compreender um determinado assunto. Logo, quando o educando se depara com dificuldades em aprender aquele conteúdo, começa a perder a confiança em sua capacidade, gerando um sentimento de baixa auto-estima. Sem acreditar em sua potencialidade, o aluno se sente desmotivado e passa a buscar outras formas de se realizar na escola, o que poderá desencadear a indisciplina. Por isso, trabalhar os conteúdos de forma crítica é importante tanto para despertar o interesse do aluno e evitar a indisciplina, como também para educar indivíduos conscientes.

\subsubsection{O sistema educacional e a escola}

O sistema educacional impõe um padrão tradicional de condutas rígidas que as instituições devem seguir e que, muitas vezes, estão fora da realidade particular de cada escola. Ainda que os professores tentem trabalhar sob essas normas, elas acabam causando tensão e desmotivando os profissionais para qualquer iniciativa.

Algumas imposições colocadas pelo sistema escolar são do conhecimento comum: escolas superlotadas, turmas numerosas, carteiras de sala de aula quebradas, falta de material didático, exigências de trabalhos burocráticos excessivos aos professores, remuneração insatisfatória, mudanças constantes de paradigmas educacionais, dentre outros. Há, também, fatores de estrutura física da escola, como: edifícios impróprios e degradados, sala de aula apertada e quente, com pouca ventilação e pouca iluminação, sala que sofre interferência do barulho de fora. Tudo isso, com certeza, irá interferir negativamente no comportamento dos alunos.

A escola, nas últimas décadas, passou por transformações que interferiram diretamente em sua dinâmica, aumentando a incidência da indisciplina. Um dos indícios dessa transformação foi o aumento efetivo do número de vagas para o ensino fundamental e médio. A democratização da escola ocorreu sem que houvesse previamente uma 
estrutura básica que garantisse: a) acomodação adequada para os educandos (escolas e salas de aula com instalações apropriadas, carteiras escolares decentes e suficientes, espaço para recreação, entre outros aspectos); b) condições dignas de trabalho para o professor (materiais didáticos, mobiliário adequado e equipamentos necessários); c) preparação do professor para lidar com as diferentes realidades dos educandos; d) qualidade da educação oferecida.

Nesse contexto, a escola dificilmente poderá ser considerada um local agradável e, assim, para muitos alunos, frequentar a escola passa a ser uma obrigação, já que ela não tem atrativos e é uma imposição dos pais. Como a criança não vê saída para essa imposição, ela cria as mais diversas estratégias para amenizar a situação "desagradável" de sala de aula e frequenta a escola tendo em vista dois objetivos: divertirse e ser aprovada. A aprendizagem e o conhecimento passam a ser ignorados.

É certo que alguns educadores/diretores, conscientes da necessidade de mudar esse quadro, empenham-se para tornar a escola um ambiente agradável e estimulante para a aprendizagem, mas, infelizmente, essa não é a realidade da maioria. Sabemos que a educação é de responsabilidade dos governos, mas, de longas datas, estes não têm investido nela seria preciso, e esse descaso e a não priorização da educação está levando-a ao sucateamento.

\section{CONSIDERAÇÕES FINAIS}

Com o exposto podemos concluir que a indisciplina é, então, resultante de fatores não somente psico-sociais, mas, muitas vezes, pedagógicos. É bom ressaltar, também, alguns determinantes da indisciplina que podem agir concomitantemente, ou seja, vários fatores podem influenciar ao mesmo tempo a atitude das crianças, determinando o seu comportamento.

Por isso, não temos ilusão de que intervir e modificar o comportamento dos alunos seja uma tarefa fácil, mas, mesmo cientes da dificuldade do professor em exercer as inúmeras responsabilidades que lhe são atribuídas atualmente, como: ensinar, educar, agradar, diagnosticar problemas emocionais, afetivos, físicos, distúrbios mentais, não podemos ficar de braços cruzados, esperando que a iniciativa seja sempre dos órgãos públicos educacionais. É preciso, dentro das nossas possibilidades, criar estratégias para 
intervir frente aos problemas que se manifestam dentro da escola, sejam eles de qualquer natureza, que prejudicam o processo ensino-aprendizagem.

Temos que considerar o fato de que, apesar de a escola estar inserida em um contexto em que os problemas sociais estão cada vez mais presentes na vida das pessoas e eles interferirem diretamente nas relações dentro dessa instituição, não podemos entendêla apenas como receptora, mas também como agente de modificação desse sistema.

É certo que o professor sozinho, sem o apoio dos colegas, da coordenação e da direção não tem condições de fazer grandes modificações em sua prática pedagógica, pois ele está submetido às normas do sistema educacional, que, por sua vez, tem sua parcela de responsabilidade pelos conflitos gerados na instituição. Porém, dentro de sua sala de aula, o professor pode criar situações que acredita serem necessárias para o bom comportamento e desempenho de seus alunos.

Não há dúvidas de que para amenizar a indisciplina na escola a melhor estratégia da qual podemos lançar mão é a elaboração e implantação de um Projeto Político-Pedagógico compartilhado, que seja capaz de prever e prevenir os problemas corriqueiros da escola. Porém, para fazer funcionar esse projeto, é preciso contar com profissionais comprometidos com a qualidade da educação: diretor, coordenador pedagógico e professores devem trabalhar juntos para o alcance das metas.

A junção de um Projeto Político-Pedagógico com a atuação de uma "autoridade competente" (OLIVEIRA, 2005) em sala de aula que desenvolva um trabalho fundamentado nos princípios de igualdade e responsabilidade poderá fazer emergir uma disciplina num contexto democrático, criando na escola um clima favorável à aprendizagem e à convivência em grupo, bem como a formação de homens participantes e responsáveis por sua própria história.

\section{Referências}

BRASIL. Ministério da Educação e do Desporto. Secretaria de Educação Fundamental. Referencial curricular nacional para a educação infantil. Brasília, 1998.

CARRAHER, Terezinha Nunes. Sociedade e inteligência. São Paulo: Cortez, 1989.

; CARRAHER, David William; SCHLIEMANN, Analúcia. Na vida dez, na escola zero. São Paulo: Cortez, 1993. 
DAVIS Claudia; LUNA, Sergio A. A questão da autoridade na educação. Cadernos de Pesquisa. São Paulo, n. 76, p. 65-70, fev. 1991.

D’ANTOLA, Arlette (Org.). Disciplina na escola: autoridade versus autoritarismo. São Paulo: EPU (Temas básicos de educação e ensino), 1989.

FREIRE, Paulo. Pedagogia da autonomia: saberes necessários à prática educativa. São Paulo: Paz e Terra, 1997.

JESUS, Saul Neves de. Como prevenir e resolver o stress dos professores e a indisciplina dos alunos? Cadernos do CRIAP, Portugal: Edições Asa, p. 44-62, 1999.

JOSÉ, Elizabette da Assunção; COELHO, Maria T. Problemas de aprendizagem. São Paulo: Ática, 2006.

KHOURI, Yvonne. Disciplina versus antidisciplina. In: D’ANTOLA, Arlette (Org.). Disciplina na escola: autoridade versus autoritarismo. São Paulo: EPU, 1989. p. 41-48. OLIVEIRA, Maria Izete de. Indisciplina escolar: representação social de professores que atuam no ensino fundamental da Cidade de Cáceres/MT. 2002. 170f. Tese (Doutorado) - Programa de Estudos Pós-Graduados em Educação: Psicologia da Educação, Pontifícia Universidade Católica de São Paulo, 2002.

. Indisciplina escolar: determinações, consequências e ações. Brasilia: Liber Livro, 2005.

STRECHT, Pedro. Crianças e adolescentes violentos: o que devemos saber para prevenir e atuar. In: SAMPAIO, Daniel (Org.). Indisciplina e violência na escola. Lisboa: PAEDC, Cadernos de Criatividade, n. 3, 2001. p. 17-30.

WOODS, Peter. Ser criativo em relação ao comportamento desviante na escola. In: SAMPAIO, Daniel (Org.). Indisciplina e violência na escola. Lisboa: PAEDC, Cadernos de Criatividade, n. 3, 2001, p. 55-78.

\section{Pedagogical and psycho-social factors of indiscipline: from childhood to adolescence}

\footnotetext{
Abstract

This paper brings to light the discussion of a topic that, since a few decades, is interfering in a negative way in the pedagogical practice of education professionals, thus
} 
causing conflicts not only in the teacher-student relationship, but in relationships within the institutions as well. We first briefly discuss the concept of discipline and indiscipline defending a democratic posture on the part of teacher and involvement of the student. Secondly, we deal with some pedagogical and psycho-social factors that interfere in child behavior and that eventually culminate in indiscipline in the classroom and at school; at the same time, we present some proposals for prevention and control of indiscipline.

Keywords: Indiscipline. Psycho-social factors. Pedagogical factors.

\title{
Les facteurs psycho-sociaux de l'indiscipline : de l'enfance à l'adolescence
}

\begin{abstract}
Résumé
Ce travail soulève la discussion d'un thème qui, cela dure quelques décennies, vient interférer de forme négative dans la pratique pédagogique des professionnels en éducation, causant des conflits non seulement dans la relation élève- maître mais aussi dans les relations entre les institutions. Nous discutons, en premier lieu et brièvement, le concept de discipline et d'indiscipline, défendant une posture démocratique de la part du maître et participative de la part de l'élève. Dans un second temps, nous abordons quelques facteurs psycho-sociaux et pédagogiques qui interfèrent dans le comportement de l'enfant et qui finissent par culminer en indiscipline dans la salle de classe et à l'école; en même temps, nous présentons quelques propositions de prévention et de contrôle de l'indiscipline.
\end{abstract}

Mots clefs : Indiscipline. Facteurs psycho-sociaux. Facteurs pédagogiques.

\section{Fatores psicosociales y pedagógicos de la indisciplina: de la infancia a la adolescencia}

\section{Resumen}

El presente texto discute un tema que, hace algunas décadas, viene interferiendo de forma nagativa en la prática pedagógica de los profesionales de la educación, causando conflitos, no sólo en relación profesor-alumno, pero también en las relaciones dentro de las instituciones. Discutimos, primeramente, de forma breve, el concepto de disciplina e 
indisciplina defendiendo una postura democrática por parte del profesor y participativa por parte del alumno. En un segundo momento, abordamos algunos fatores psicosociales y pedagógicos que interferen en el comportamiento del niño y que resultan en indisciplina en la clase y en la escuela; al mismo tiempo, presentamos algunas propuestas de prevención y control de la indisciplina.

Palabras-clave: indisciplina. Fatores psicosociales. Fatores pedagógicos.

Recebido em: 05.01.2009

Aceito em: 11.09.2009 